\title{
A RESISTÊNCIA SINDICAL FRENTE ÀS INOVAÇÕES LEGISLATIVAS DIRECIONADAS À REGULAÇÃO DO TRABALHO: UM DEBATE A PARTIR DA EXPERIÊNCIA BRASILEIRA
}

\section{Rafael da Nóbrega Alves Praxedes* Gerardo Clésio Maia Arruda*}

Resumo: Neste artigo reflete-se acerca do sindicalismo brasileiro que, após o getulismo e influenciado pela Carta del Lavoro, passou a se orientar pelo princípio da unicidade sindical. As relações de trabalho sofrem, desde fins do século XX, alterações que vem provocando crise no sindicalismo e o fortalecimento do discurso da flexibilização. Apoiado em pesquisa bibliográfica e documental, analise-se a reforma trabalhista brasileira de 2017, objetivando compreender as determinações da frágil resistência sindical a nova legislação, claramente cerceadora de direitos historicamente conquistados. Conclui-se que é mister uma mudança na organização dos trabalhadores para se contrapor a uma crescente precarização das leis trabalhistas.

Palavras-chaves: Direito do Trabalho. Sindicalismo. Flexibilização. Precarização. Projeto de Lei 6.787/2016

\section{SYNDICAL RESISTANCE IN THE FACE OF LEGISLATIVE INNOVATIONS DIRECTED TO LABOR LAWS: A DEBATE COMING FROM THE BRAZILIAN EXPERIENCE}

Abstract: This article analyze the Brazilian syndicalism that, after getulism and being influenced by the Carta del Lavoro, began to be guided by the of syndical oneness. Since the end of last century, labor relations have undergone changes that have being provoking acrisis in syndicalism and strengthening the flexibilization discourse. Supported by bibliographical and documentary research, the Brazilian labor reform is analyzed, with the aim of understanding the determinations of the fragile syndical resistance to the new legislation that restricts historically conquered rights. Concludes that a change in the organization of workers is required to counteract the precarization of labor laws.

Keywords: Labor Law. Syndicalism. Flexibilization. Precarization. Bill 6.787 / 2016

\section{INTRODUÇÃO}

O trabalho imaterial vem se ampliando, desde os anos 1980, de forma quantitativa e qualitativa. Nas sociedades desenvolvidas e nas emergentes a riqueza produzida no setor de serviços já ultrapassou largamente a riqueza produzida no setor industrial e demais setores da

\footnotetext{
${ }^{*}$ Mestrando em Direito e Desenvolvimento (UNICHRISTUS), pós-graduado lato senso em Direito e Processo do Trabalho. Advogado.rafaelpraxedesadv@gmail.com

* Professor do Programa de Mestrado em Direito do Centro Universitário Christus (UNICHRISTUS) e Professor Titular da Universidade de Fortaleza (UNIFOR). Doutor e Mestre em Sociologia, Especialista em Geografia e Graduado em Ciências Econômicas. clesioarruda@yahoo.com.br
}

Rev. de Movimentos Sociais e Conflitos | e-ISSN: 2525-9830 | Porto Alegre | v. 4 | n. 2 | p. 84 - 104 | Jul/Dez. 2018 
economia, de sorte que se observa nas inumeráveis atividades de serviços a formação da parcela mais significativa do Produto Interno Bruto (PIB) mundial. Portanto, tem-se nos serviços, contemporaneamente, o lugar principal da produção da riqueza e da ocupação de força de trabalho.

Esta tendência já consolidada da economia mundial deve se ampliar cada vez mais aceleradamente, uma vez que a cada rodada de inovação tecnológica verifica-se que as atividades que requerem esforço físico têm cedido espaço para as máquinas e equipamentos. Com efeito, as atividades que dependiam da força humana estão sendo robotizadas, com isto assiste-se ao desaparecimento dos grandes contingentes de trabalhadores operários, que executavam atividades rotineiras, de operações simples, que se identificavam no exercício de suas atividades, em seus cotidianos, nos seus hábitos e em suas visões de mundo. Enquanto, por outro lado, têm-se um deslocamento do capital para as atividades de serviços, que se coloca hoje como a alternativa para a valorização do capital e emprego da força de trabalho disponível, dada a maior dificuldade para a substituição do trabalho humano e porque neste setor econômico é mais elástica a possibilidade de oferta de novos produtos.

As grandes fábricas com o modelo de produção que absorvia vastos contingentes de operários, semelhantes em suas atividades, em suas remunerações, em seus benefícios recebidos e nas dificuldades resultantes de seus contratos de trabalho, favoreceram ao surgimento das grandes organizações sindicais. A superação deste paradigma de produção está erodindo a base de sustentação dos sindicatos. Em suma, está ocorrendo o desaparecimento das categorias profissionais que eram extremamente numerosas e se verificando o surgimento de novas atividades laborais distintas nas tarefas que a caracterizam. Com efeito, a fragmentação da produção, a sua flexibilização concernente ao sistema de produção e ao produto ofertado, está se reproduzindo na organização e hierarquização do trabalho.

Este cenário, que se observa na economia mundial, impacta sobremaneira a economia brasileira, sua produção, seu trabalho, e, por conseguinte, a organização sindical. Eis aí o que justifica os avanços dos ideais neoliberais que se consolidam inexoravelmente em várias sociedades, bem como das dificuldades da promoção da unidade de trabalhadores em torno de ideais comuns, da construção de bandeiras de lutas, do combate a desmobilização de direitos e

Rev. de Movimentos Sociais e Conflitos | e-ISSN: 2525-9830 | Porto Alegre | v. 4 | n. 2 | p. 84 - 104 | Jul/Dez. 2018 
garantias conquistadas, principalmente, após a grande crise de 1929 até o final dos anos 1970, considerado o período áureo do welfare state.

No Brasil, de maneira açodada, sem uma ampla discussão com setores da sociedade diretamente vinculados ao tema, se trouxe ao plenário da Câmara Federal uma proposta de "Reforma Trabalhista", em novembro de 2017, sob os auspícios de instituições representativas do grande capital, que alterou profundamente a Consolidação das Leis do Trabalho (CLT), subtraindo direitos que de há muito resistiam a investidas de "reformistas" e retirando dos sindicatos sua principal fonte de custeio: a contribuição sindical obrigatória.

Com base nesta recente inovação legislativa, buscar-se-á compreender as causas determinantes desta fragilidade do movimento sindical, mas, sobretudo, far-se-á um esforço no sentido de analisar o sistema sindical brasileiro, na forma prevista no ordenamento nacional, e a sua adequabilidade aos desafios advindos com as transformações no mundo do trabalho. Tem-se, assim, a seguinte questão norteadora: quais as causas da apatia e da frágil resistência do sindicalismo brasileiro diante de uma Reforma Trabalhista claramente prejudicial aos interesses dos trabalhadores e dos próprios sindicatos?

$\mathrm{O}$ artigo está constituído de três tópicos; no primeiro, aborda-se o nascimento do sindicalismo ligado ao surgimento do capitalismo industrial, a sua busca constante do aumento da produção e da produtividade, enfim, da adoção da ciência à organização do trabalho; no segundo tópico, aborda-se a formação do sindicalismo brasileiro, referenciando especialmente o período do governo de Getúlio Vargas e as alterações propugnadas pela Constituição Federal de 1988, além do que, faz-se um cotejamento da crise do sindicalismo diante das mudanças na organização do trabalho; no terceiro tópico, com base na passagem do modelo organizacional rígido para o modelo flexível, discute-se a centralidade do trabalho na organização da sociedade e explicita-se o discurso da necessidade de flexibilização das leis trabalhistas, suas ideias âncoras e a crítica que denuncia a ideologização presente neste discurso que confunde modernização e precarização das leis trabalhistas; no quarto tópico, faz-se um breve histórico do processo legislativo que culminou na aprovação Reforma Trabalhista de 2017, buscando-se entender os motivos da inércia dos sindicatos frente a lesiva alteração da lei trabalhista para os trabalhadores e entes sindicais brasileiros.

\section{INDUSTRIALIZAÇÃO, PRODUTIVIDADE E LUTA OPERÁRIA}

Rev. de Movimentos Sociais e Conflitos | e-ISSN: 2525-9830 | Porto Alegre | v. 4 | n. 2 | p. 84 - 104 | Jul/Dez. 2018 
Entende-se por produtividade o incremento da produção medido em relação à unidade de trabalho ou de capital. Portanto, aumento ou ampliação da produtividade significa a elevação do valor da produção mantendo-se estático o trabalho e o capital; podendo ser obtida ainda por intermédio de uma elevação de uma dessas variáveis ou ambas, mas numa proporção inferior à variação da produção (FEIJÓ e CARVALHO, 1994).

A discussão acerca da produtividade evoca a temática do desenvolvimento científico, pois foi o acumulo de conhecimentos que viabilizou a substituição das forças musculares, humanas e animais, pelas energias anorgânicas da natureza nos processos de produção, transporte, comunicação, etc. Nesse sentido, ao se referenciar a produtividade, deve-se ter a Revolução Industrial como horizonte das primeiras sistematizações no caminho de uma efetivação concreta e significativa de diferenciais de produção (BELTRÃO, 1965). Com a Revolução Industrial, a humanidade passou a vivenciar um espetacular período de desenvolvimento, que se alicerçou no crescimento contínuo e acelerado da força motriz. Noutros termos, este evento inaugurou as condições essenciais para se obter uma elevação radical da força energética e um aprimoramento substancial da base técnica.

Enfim, a busca da produtividade remonta ao capitalismo industrial nascente. Smith (1981) já demonstrava esse fenômeno quando de sua análise da divisão do trabalho numa fábrica de alfinetes, e do confronto da produtividade do trabalho nestas condições com a de um homem produzindo isoladamente. De acordo com Adam Smith, a produção alfinete/homem, no sistema de divisão do trabalho, supera em quarenta e oito mil alfinetes por dia a produção no sistema individual. O economista liberal revela que a disciplinarização, especialização e o emprego da maquinaria no processo de produção são fatores revolucionários da produção industrial (HEILBRONER, 1988).

Gorz (1989), ao analisar as técnicas de produção e a organização do trabalho no capitalismo industrial, mostra a busca permanente da ampliação da produtividade como sendo um objetivo imposto despoticamente, que se dá eminentemente por intermédio da intensificação do trabalho. Além do que, sustenta a seguinte a tese: a organização da produção é realizada de forma a transmitir para o operário a ideia de que a pressão por um máximo de rendimento contínuo é uma exigência intrínseca da máquina. Assim, pode-se dizer que a organização do trabalho é realizada de forma opressiva porque busca incessantemente a 
exacerbação da acumulação de capital, já que se tenciona com a organização opressiva a obtenção do máximo de rendimento dos fatores de produção.

Vale destacar ainda a abordagem weberiana do racionalismo burocrático, que busca compreender a magnitude da produtividade a partir do fenômeno da burocratização. De acordo com Hall (1978), a burocracia pode ser definida como uma organização formada:

Por uma complexa divisão do trabalho; uma estrutura hierárquica multigraduada e rigorosamente observada; normas extensivas de controle de atuação no trabalho; normas de trabalho bem desenvolvidas e sistematicamente observadas; comportamento impessoal - tanto sobre os membros da organização como entre estes e os não membros - orientado por normas que enfatizam o cargo e não o ocupante como base de interação; e a importância do êxito no desempenho das tarefas - em oposição aos sentimentos - como base para a promoção e salário. (HALL, 1978, p. 33).

Um dos principais aspectos que corroboram com a racionalidade burocrática e a sua eficiência é a divisão do trabalho. Na verdade, para se atingir o objetivo de rendimento elevado, denunciado por Weber (1991) como um dos principais objetivos da burocracia, a organização burocrática radicaliza o processo de especialização, ou seja, divide as tarefas até torná-las rotineiras, a tal ponto que as simplificações das tarefas possibilitem sua realização por indivíduos dotados de um mínimo de preparo intelectual. Nesse sentido, a ética da eficiência presente na organização produtiva tem como pressuposto essencial a racionalização e a objetivação do trabalho humano. Mas uma racionalização empobrecida, porque leva ao extremo a separação entre a operação e o planejamento, e especializa de tal forma as atividades que as torna idiotizantes.

Adorno e Horkheimer (1991) resumem a discussão da apropriação capitalista da ciência na afirmação de que a essência do saber é a técnica. Noutras palavras, o objetivo precípuo da ciência é desenvolver-se metodologicamente, no intuito de viabilizar a acumulação de capital por intermédio da exploração do trabalho. Com efeito, residem aí os aspectos fundantes da utilização racional do conhecimento científico, ou seja, da transformação da ciência em força produtiva.

Marcuse (1973) identifica no racionalismo industrial a gestação de irracionalidades engendradas no esteio da busca da eficiência e do progresso. Isto porque são características da sociedade industrial, a destruição crescente que resulta da ampliação da produtividade, a 
dominação coercitiva do pensamento e das esperanças pelos poderes existentes e a manutenção da miséria diante do continuado crescimento da riqueza. Além do que, a base produtiva da moderna sociedade tem uma tendência totalitária que se expressa quando demanda especificamente habilidades e atitudes, bem como quando determina as necessidades e aspirações individuais. Por conseguinte, pode-se afirmar que a tecnologia é também um sistema de dominação, uma vez que o sentido de racionalidade da tecnologia é negado pelas irracionalidades resultantes e sua utilização produtiva, ou seja, pela extensão do controle da natureza à sociedade $\mathrm{e}$ ao homem.

No capitalismo industrial, a dominação é realizada pelo aparato administrativo, que integra a gerência científica com o maquinário. A integração desses fatores, no processo administrativo, da forma e conteúdo à racionalidade tecnológica e, por conseguinte, à produtividade daí derivada, via intensificação e autonomização do trabalho, resulta na supressão da liberdade. Isto ocorre porque, na verdade, a existência individual, enquanto instrumento, coisa ou objeto, é essencialmente uma forma de servidão.

A luta operária contra a exploração do capitalismo industrial remonta à sua gênese. Num primeiro momento, os operários se insurgiam contra a extensão da jornada de trabalho, ou seja, contra a extração da mais-valia absoluta; posteriormente, com a introdução de técnicas visando a racionalização e intensificação do trabalho, os operários passaram a se rebelar contra a busca pela ampliação da mais-valia relativa ${ }^{1}$. É nesta última forma que se enquadra a resistência de que sempre foi alvo o taylorismo ${ }^{2}$, que já nos seus primórdios

\footnotetext{
${ }^{1}$ Karl Marx explicita o processo de produção da mais-valia no cerne do modo de produção capitalista quando discute a fórmula geral do capital. Para Marx, é na conversão do dinheiro em mercadoria e reconversão de mercadoria em dinheiro (D-M-D), que se viabiliza a transformação em capital que dá início à acumulação, bem como à ampliação da grandeza do valor inicial. Ressalte-se que, embora não haja diferença qualitativa nos extremos dessa fórmula, pois são igualmente dinheiro, o dinheiro resultante no final do circuito é superior ao utilizado no início. Por isso, a fórmula completa se define como: D-M-D', onde $\mathrm{D}^{\prime}=\mathrm{D}+\Delta \mathrm{D}$. De acordo com Marx (1987, p. 170), "esse acréscimo ou o excedente sobre o valor primitivo chama-se de mais-valia (excedente). $\mathrm{O}$ valor originalmente antecipado não só se mantém na circulação, mas nela altera a própria magnitude, acrescenta uma mais-valia, valoriza-se. E neste movimento transforma-o em capital". A mais-valia pode ser denominada de absoluta ou relativa. No modo de produção capitalista, quando o proprietário dos meios de produção exerce uma coerção sobre o trabalhador, para que ele dispenda sua força de trabalho além da quantidade equivalente ao valor de seu salário, buscando, assim, extrair um sobre trabalho - está-se produzindo mais valia absoluta. Por outro lado, a organização social do processo de produção - a divisão do trabalho no interior da fábrica -, o uso cada vez mais intensivo e eficiente da maquinaria e a aplicação da ciência, em suma, o desenvolvimento das forças produtivas é o motor gerador da produção da mais-valia relativa.

${ }^{2}$ Frederick Winslow Taylor desenvolveu suas teorias sobre a racionalização do processo de trabalho alicerçado em estudos e experiências concretas, que ele teve oportunidade de realizar por intermédio de seu contato direto com o sistema produtivo fabril. Rago e Moreira (1987) informam que Taylor adquiriu seus conhecimentos sobre o processo produtivo quando de sua experiência no desenvolvimento das atividades de chefe-ferramenteiro,
}

Rev. de Movimentos Sociais e Conflitos | e-ISSN: 2525-9830 | Porto Alegre | v. 4 | n. 2 | p. 84 - 104 | Jul/Dez. 2018 
enfrentou uma forte resistência da classe trabalhadora, que via nesse modelo organizacional uma forma de sobre-exploração do trabalho.

O próprio Taylor (1963), ao relatar a experiência da implantação de seu método na Mindvale Stell Co., explica algumas formas de reação postas em prática pelos operários, que, segundo ele, ia desde a quebra intencional das máquinas, com o objetivo de mostrar que o ritmo intenso era prejudicial aos equipamentos, até a ameaça de agressão aos colegas que colaboravam com a gerência, e mesmo a ameaça de morte. Segundo Taylor, esta era uma prática da qual ele mesmo foi vítima.

Rago e Moreira (1987) fornecem vários exemplos de manifestações da classe trabalhadora contra a organização despótica do trabalho, quando do período de intensificação da produção industrial na Europa. Dentre outras, citam a greve dos mineiros (1897), a dos mecânicos e trabalhadores do aço (1901) e a greve dos trabalhadores dos matadouros (1904). Por outro lado, era também comum reações e atos de violência contra ocupantes de cargos de supervisão, que ganharam maior expressão com a introdução das técnicas racionalizadoras da produção. As ocupações mais visadas pelos movimentos dos trabalhadores eram aquelas que controlavam e/ou mensuravam a produção, assim como, os cronometristas e apontadores.

Nesse cenário, emergiram as primeiras organizações sindicais. Com efeito, o sindicalismo, como organização de trabalhadores, surge historicamente ligado ao desenvolvimento do capitalismo industrial (ROMITA, 2002). No início do século XX, os sindicatos foram responsáveis pela conquista de vários direitos dos trabalhadores, "tais como a limitação da jornada diária, semanal e das horas extras, a instituição do descanso semanal, do intervalo intrajornada e interjornada" (PORTO, 2016). Com grande capacidade de articulação política, por conta do interesse comum dos trabalhadores da grande indústria, o poder dos sindicatos aumentou consideravelmente no decorrer do século $\mathrm{XX}$, havendo, nesse período, a obtenção de inúmeros novos direitos para a classe operária.

segundo contramestre, contramestre, chefe-mecânico, diretor de pesquisa e engenheiro-chefe das Usinas Mindvale Steel Co. Apoiado nessa experiência, Taylor elaborou um método de administração, que tem como premissas básicas a intensificação do trabalho e a transferência do controle do processo de trabalho para a gerência. Para Rago e Moreira (1987), Taylor fez isso por acreditar que a ampliação e a complexificação das fábricas, como resultado da concentração dos capitais, passavam a demandar uma gerência científica do trabalho, compatível com as exigências desse capitalismo monopolista emergente. Taylor propunha então uma gerência que pudesse ao mesmo tempo exercer um controle estreito sobre o trabalhador, que devido ao seu "instinto natural para a vadiagem" produz sempre aquém do seu potencial, e organizar a produção de modo a possibilitar a consecução de produtos competitivos.

Rev. de Movimentos Sociais e Conflitos | e-ISSN: 2525-9830 | Porto Alegre | v. 4 | n. 2 | p. 84 - 104 | Jul/Dez. 2018 


\section{BREVES CONSIDERAÇÕES ACERCA DO SINDICALISMO BRASILEIRO}

De acordo com Almeida (1996), no Brasil, entre os anos 1920 e 1930, a indústria que se encontrava em processo de franco desenvolvimento concedia empregos para pessoas que vinham do campo para a cidade. Entretanto, eram postos de trabalho que submetiam os trabalhadores a péssimas condições de labor com extenuantes jornadas de trabalho, baixa remuneração e trabalho infantil, revelando uma conjuntura de exploração desmedida do proletariado. Nesse período, movimentos de trabalhadores como a greve eram vistos como crime pelas autoridades policiais e não havia, ainda, uma preocupação com o reconhecimento de direitos trabalhistas.

A partir dos anos 1930, com a ascensão de Getúlio Vargas ao poder, observa-se o início de um governo ligado a questões trabalhistas com a criação do Ministério do Trabalho, Indústria e Comércio e da publicação da chamada Lei da Sindicalização em 1931. Tratava-se de um novo período do ponto de vista econômico e social, especialmente pelo crescimento significativo da industrialização no Brasil e pela atenção aos direitos dos trabalhadores tratados de maneira inédita até então (IGLESIAS, 1993).

No governo de Vargas, deixando à margem o debate acerca do mérito ou não de sua habilidade, é fato que o aumento da produção industrial se deu de forma extraordinária nos anos que se seguiram, apresentando um crescimento, muitas vezes, na casa dos dois dígitos (FARIA; BARROS, 1983). Por outro lado, neste período, verificou-se um avanço significativo dos sindicatos, marcados por forte influência do modelo corporativista italiano baseado na Carta del Lavoro criada por Mussolini no ano de 1927 (BELTRAN, 1998, p. 7071). Em função da importação do modelo sindical italiano, os sindicatos no Brasil são impregnados pelo poder do próprio Estado.

Deve-se ressaltar que a Constituição de 1934 buscou trazer um modelo sindical democrático, acolhendo os princípios da liberdade e pluralidade sindical, contudo, já em 1937, com uma nova constituição, houve o retorno à corrente italiana, substituindo-se a pluralidade pela unicidade sindical (LEBRE, 1999, p. 59). Iglesias (1993) pontua, entretanto, que o modelo sindical previsto pela Constituição de 1934 não passou de um arcabouço teórico, sendo que, de fato, os sindicatos sempre foram controlados pelo governo, situação que se agravou ainda mais com o início do período conhecido como Estado Novo; quando os

\footnotetext{
Rev. de Movimentos Sociais e Conflitos | e-ISSN: 2525-9830 | Porto Alegre | v. 4 | n. 2 | p. 84 - 104 | Jul/Dez. 2018
} 
sindicatos, fundados no princípio da unicidade sindical, foram utilizados por Vargas com viés eminentemente político Isto porque, ao conceder vários novos direitos aos trabalhadores, o chefe do Poder Executivo via sua popularidade crescer, solidificando sua imagem de "pai dos pobres".

Faria e Barros (1983) assinalam que durante o período do Estado Novo, apenas sindicatos reconhecidos pelo Governo poderiam representar uma determinada categoria, sendo expressamente proibida a prática da greve. Houve, ainda, a definitiva submissão dos sindicatos ao Estado por meio da Lei Sindical de 1939, que determinou a existência de apenas um sindicato por cada categoria e condicionou o funcionamento da entidade sindical a uma "carta de reconhecimento", expedida pelo órgão ministerial. Os autores, apontam ainda o imposto sindical obrigatório como um dos fatores que contribuíram para a sujeição dos sindicatos perante o Estado.

Os sindicatos brasileiros, dessa forma, foram sedimentados no tempo como entidades de cunho eminentemente corporativista, ou seja, nesses órgãos apenas filiavam-se empregados que desempenhavam a mesma função. Em termos culturais, criou-se uma separação entre as diversas categorias de empregados, cada uma preocupada apenas com seus próprios interesses. Além disso, outra característica marcante dos sindicatos brasileiros, desde o nascedouro, foi a subordinação perante o Estado que controlava as entidades sindicais de acordo com seus interesses.

A Constituição Federal de 1988, apesar de alguns avanços, dentre outros, a liberdade da associação sindical sem a necessidade de autorização do Estado, manteve o princípio da unicidade, proibindo a existência de mais de um sindicato da mesma categoria profissional ou econômica por base territorial. Nascimento (2009) avalia que, apesar de a Constituição de 1988 ter sido um avanço no que diz respeito ao sindicalismo brasileiro, tendo em vista sua feição eminentemente democrática, a manutenção da unicidade sindical e da contribuição sindical obrigatória escancaram a forma contraditória da organização sindical no Brasil.

Nem mesmo a Constituição Cidadã, portanto, foi capaz de quebrar completamente a influência da Carta del Lavoro sobre os sindicatos brasileiros que seguem com seu aspecto corporativista e são obrigados a obedecer ao princípio da unicidade sindical. No Brasil, onde os sindicatos são tradicionalmente organizados apenas por ramo de atividade, não há como esperar grande contribuição dado o panorama atual, visto que "o modelo sindical brasileiro é

Rev. de Movimentos Sociais e Conflitos | e-ISSN: 2525-9830 | Porto Alegre | v. 4 | n. 2 | p. 84 - 104 | Jul/Dez. 2018 
atrasado e pouco representativo, todos sabem à exaustão, com a existência de uma miríade de sindicatos com pouca ou nenhuma legitimidade perante a classe” (RIBEIRO, 2017).

Estes fatores, sem dúvidas, contribuem para a crise do movimento sindical. Contudo, é inegável, também, o papel que a globalização da economia exerceu, e ainda exerce, sobre o sindicalismo (ROMITA, 2002). Desde as últimas décadas do século XX, tem-se observado um movimento de individualização do ser humano como um fim em si mesmo e isso deságua nas relações de trabalho - não se observando mais sequer uma homogeneidade entre os empregados de uma mesma categoria econômica e, muito menos, aquele "interesse comum" a todos os empregados, típico da era pós-revolução industrial quando a quase totalidade trabalhavam dentro das fábricas. Como explicita Manuel Castells (2016, p.326), a reestruturação produtiva, alicerçada na tecnologia da informação, "está introduzindo uma transformação fundamental: a individualização do trabalho no processo de trabalho." Fato este que contraria a tendência histórica do assalariamento do trabalho, característica fundante da era industrial.

Com a transformação do trabalho, houve uma verdadeira fragmentação das categorias em diversos setores. Isso afetou diretamente o sindicalismo, pois este não é mais capaz de reunir trabalhadores em torno de um objetivo comum (VASCONCELOS FILHO; CAMARA, 2017). Diante disso, como afirma Sorj (2000), coloca-se um problema em relação aos sindicatos e seu papel diante das mudanças no próprio trabalho que é visto, cada vez mais, do prisma individual: qual deve ser o papel do sindicalismo, partindo da individuação das relações de trabalho e pouca homogeneidade entre os empegados? Possuem os sindicatos força política suficiente para exercer o papel de luta pelos direitos dos trabalhadores e, em última análise, pela sua própria sobrevivência diante de uma precarização do trabalho disfarçada de modernização e flexibilização das leis trabalhistas?

\section{FLEXIBILIZAÇÃO OU PRECARIZAÇÃO DAS LEIS E DAS CONDIÇÕES DE TRABALHO?}

Estudos realizados no final do século XX passaram a alevantar uma questão fundamental acerca da categoria trabalho, ou seja, discutem se a posição do indivíduo no sistema produtivo continua sendo um fator configurador de sua posição social, política e cultural. Deluiz e Trein (1991) mapeiam e sistematizam algumas reflexões teóricas 
indicadoras de posições antagônicas no que concerne ser a categoria trabalho ainda fundamental para a compreensão da sociedade. Segundo os autores, existe uma corrente teórica que sustenta que a sociedade do trabalho chegou a seu fim, e uma outra que defende a existência de uma crise que modifica e dá novo conteúdo a aspectos do mundo do trabalho.

O fim da sociedade do trabalho é anunciado por Habermas (1987) quando discute e aponta aspectos denotadores do esgotamento dos ideais utópicos alicerçados nesse modelo de sociedade. De acordo com este filósofo, este fato se evidencia na comprovação empírica da ineficiência do trabalho, da produção e do lucro na construção de um desenvolvimento social harmônico. Em suma, a ampliação exacerbada dos investimentos em racionalização, que marcou a segunda revolução industrial, resultou numa expansão radical da produtividade do trabalho, ao mesmo tempo em que intensificou a secular tendência de redução do tempo de trabalho socialmente necessário. Estes elementos denunciam um futuro negativo ou mesmo o fim da utopia da sociedade do trabalho, à medida que apontam uma tendência para a cristalização e o aprofundamento dos problemas sociais; assim como, o empobrecimento estrutural dos países em desenvolvimento, o desemprego e os desequilíbrios sociais crescentes nos países desenvolvidos.

Contrapondo-se a este entendimento, Deluiz e Trein (1991) levanta que o trabalho ainda possui um valor fundamental para uma parte significativa da classe trabalhadora, em especial para aqueles que formam as camadas inferiores da população. Defendem ainda os autores que o sistema produtivo está sofrendo alterações que impactam sobremaneira as estruturas e a dinâmica organizacionais, mas alerta que, paralelamente a uma nova racionalidade da produção, subsistem técnicas e conceitos de orientação eminentemente tayloristas. Portanto, muito embora estes autores concordem que se assiste a uma nova racionalização produtiva, que modifica substancialmente o trabalho em sua organização e exploração, ele ainda persiste como uma questão relevante para a compreensão da sociedade.

Entrementes, deve-se considerar que ambas as perspectivas de análise da sociedade do trabalho diagnosticam a existência de modificações na organização produtiva. A novidade encontra na flexibilidade que se dá no processo de trabalho, com o intuito de se alcançar os objetivos de ampliação da produtividade, melhoria da qualidade do produto e variedade da produção. Para Harvey (1992), encontram-se nesses objetivos as condições viabilizadoras da superação dos modelos organizacionais rígidos pelos modelos de organização flexível.

Rev. de Movimentos Sociais e Conflitos | e-ISSN: 2525-9830 | Porto Alegre | v. 4 | n. 2 | p. 84 - 104 | Jul/Dez. 2018 
Analisando comparativamente os processos de trabalho taylorista e o flexível, observa-se que eles divergem em questões cruciais, tanto relativas ao gerenciamento da produção como dos recursos humanos. Este fato é demonstrado em aspectos primordiais do controle da produção e do trabalho; assim como, no aspecto referente ao controle da qualidade do produto, que nos modelos rígidos é uma atividade especializada e executada em partes do processo produtivo, e no modelo flexível é uma atividade completamente descentralizada e operacionalizada por todos os indivíduos participantes da produção. Também a natureza do trabalho assume características completamente opostas nos dois modelos, enquanto nos rígidos é exacerbadamente especializada, no flexível é composta por múltiplas funções ou tarefas (WOOD, 1993).

Esse movimento de transformação da produção econômica do modelo rígido para o flexível foi acompanhado por um clamor para a "flexibilização" das leis trabalhistas. Nas mais diversas sociedades passaram a se assistir uma forte investida para a efetivação de mudanças substanciais no ordenamento jurídico no concernente às relações laborais. Grande parte dos argumentos que sustentam a necessidade de relativização das leis trabalhistas se alicerçam e colocam num primeiro plano às atividades econômicas (SILVA JÚNIOR, 2017). Em uma conjuntura de elevados níveis de desemprego, grande quantidade de subempregos e transformação da economia capitalista, justifica-se a flexibilização de alguns pontos do ordenamento jurídico a fim de preservar a boa condição da empresa e a manutenção de empregos.

Em meio a demandas por mudanças radicais que se impõe aos governos de tendências à esquerda, ao centro e à direita, resiste o pensamento que defende a flexibilização gradual, que seja realizada de forma excepcional, garantindo a dignidade do trabalhador (CASSAR, 2018). Em síntese, flexibilizar leis trabalhistas não deve ser sinônimo de retirar direitos dos empregados, enxergando a relação de trabalho apenas pelo viés econômico. Alterações legislativas da regulação da relação entre o trabalho e o capital faz-se necessária diante do cenário de profundas mudanças econômicas e tecnológicas. Entretanto, é preciso ponderar que há uma fronteira tênue entre flexibilização e precarização das relações de trabalho.

Nas palavras de Boaventura de Sousa Santos (2000), a flexibilização é sinônimo de precariedade, sendo essa, inclusive, causa e efeito da perda da força e poder dos sindicatos. $\mathrm{Na}$ avaliação deste autor a flexibilização não pode se confundir com a precarização. Para 
tanto, é preciso que haja uma adequação constante dos institutos que regulamentam as relações de trabalho e emprego a fim de acompanhar o ritmo frenético de transformações contemporâneas, respeitada, sempre, a dignidade do trabalhador.

A desregulamentação do mercado de trabalho, em última análise, conforme aponta Zygmunt Bauman (2015, p. 46), é uma das causas que deixam os pobres ainda mais pobres:

A "desregulamentação" de bancos e do movimento de capital permite aos ricos deslocarem-se livremente, buscar e encontrar os melhores e mais lucrativos terrenos para exploração e, assim, ficarem mais ricos; enquanto isso, a "desregulamentação" dos mercados de trabalho torna os pobres incapazes de acompanhar essas façanhas, isso para não falar em deter ou diminuir o ritmo das peregrinações dos proprietários de capital (agora chamado investidores", no linguajar das bolsas de valores), situação que necessariamente torna os pobres mais pobres.

No Brasil, juntamente com as ideias neoliberais, nos anos 1980, emergiu no meio acadêmico e no meio empresarial teses que buscam fundamentar a necessidade de uma profunda reforma trabalhista a fim de adequar o ordenamento jurídico às novas relações de trabalho. $\mathrm{O}$ discurso formulado nestes segmentos da sociedade recebeu - e continua a receber - largo apoio da mídia tradicional, constituída dos grandes grupos de emissão de informações no rádio e na televisão (O GLOBO, 2018; FOLHA DE SÃO PAULO, 2018). Foi-se elaborando, paulatinamente, argumentos que fundamentavam a urgência de uma reforma assentada na ideia de que a lei trabalhista brasileira era velha e desatualizada, por ser da década de 1940. Clamavam que esta característica era causa, e não os fundamentos econômicos, da dificuldade de criação de novos postos de trabalho; ou seja, falaciosamente, sustentavam que as leis trabalhistas eram as responsáveis por manter os altos índices de desemprego.

Na verdade, desde os anos 1940, a Consolidação das Leis do Trabalho (CLT) sofreu alterações substanciais no seu texto, além de ter recepcionado centenas de leis trabalhistas com o objetivo de adequar o ordenamento jurídico às mudanças na ordem econômica. Contudo, o pensamento que discrimina a CLT como antiquada foi se consolidando e abrindo espaço para uma confusão entre flexibilização e precarização das leis trabalhistas brasileiras. Com efeito, as proposições de mudanças legislativas foram efetivadas sob a batuta dos representantes do capital, o que redundou na proteção de interesses de um só lado da relação

Rev. de Movimentos Sociais e Conflitos | e-ISSN: 2525-9830 | Porto Alegre | v. 4 | n. 2 | p. 84 - 104 | Jul/Dez. 2018 
trabalho-capital. Avalia Farias (2011) que esta situação acarreta no fato de que o empresariado, em busca de proteção de seus interesses, não observa a marcha da classe operária no caminho da indignidade, o que pode ocasionar distúrbios sociais e consequências negativas para a ordem democrática.

Com efeito, ajustes na legislação trabalhista se fazem necessários visando sua adequação às profundas transformações ocorridas na produção e no trabalho nas últimas décadas. Entretanto, dado a essencialidade do trabalho nas relações sociais, a sua conotação moral, trata-se de uma questão que não deve ser tratada exclusivamente na perspectiva econômica, mas também sob o viés sociocultural. Neste sentido, alterações na legislação trabalhista de ampla magnitude deve ser fruto de um debate que abarque um amplo espectro de atores e setores da sociedade. Porém, o que se assistiu recentemente no Brasil, foi a aprovação de um projeto de lei votado às pressas, sancionado sem o enfrentamento nem mesmo dos interessados mais diretos - os trabalhadores e os sindicatos.

\section{TRAJETÓRIA DO PROJETO DE LEI 6.787/2016 E SUAS CONSEQUÊNCIAS}

Após o transcurso do processo de impeachment que culminou com a saída da expresidente da República Dilma Roussef, foi implementada uma agenda de reformas pelo novo governo que elegeu a reforma trabalhista como um dos seus principais objetivos. Em agosto de 2016, Michel Temer tomou posso como novo presidente da República Federativa do Brasil; já no mês de dezembro do mesmo ano, o Poder Executivo apresentou o Projeto de Lei 6.787/2016, que, na versão original, previa mudanças pontuais na legislação trabalhista.

Ao Projeto de Lei originalmente apresentado, no decorrer de sua tramitação, foram acrescentadas pelos deputados centenas de proposições de mudanças, concernentes tanto à Consolidação das Leis do Trabalho (CLT) quanto às diversas leis esparsas que tutelam as mais variadas facetas das relações de trabalho. Com efeito, o que surgiu como um conjunto de ajustes na forma de Projeto de Lei passou a ser denominado de "Reforma Trabalhista". Como esclarece a pesquisadora Vólia Cassar (2018, p. 91), uma proposta que foi levada ao Poder Legislativo em que pontilhavam timidamente sete artigos passou por uma mudança estupenda, "não só da legislação trabalhista, mas também da estrutura do direito do trabalho, seus princípios e fundamentos." 
Após o exíguo interstício de quatro meses de discussões, aos 26 de abril de 2017, a Câmara Federal votou e aprovou a redação final do texto, enviando a matéria para análise do Senado Federal já no dia 28 de abril de 2017. No Senado Federal, a reforma trabalhista seguiu tramitando de maneira surpreendentemente rápida, tendo sido aprovado, no dia 04 de julho de 2017, requerimento de urgência para votação do projeto.

No dia 11 de julho de 2017, o plenário do Senado Federal aprovou a reforma trabalhista sem alterar uma linha do texto, rejeitando todas as emendas apresentadas; uma manobra que evitou que o projeto retornasse à Câmara dos Deputados. Com isto, o Senado federal pactuou com o Poder Executivo, que havia comunicado, por intermédio de carta escrita pelo chefe do Poder Executivo em exercício, em que prometia aos Senadores vetar alguns pontos e redigir uma Medida Provisória, no caso dos parlamentares abdicarem de legislar em prol da agilidade da aprovação final do projeto de lei.

Ressalte-se que nem mesmo a Nota Técnica apresentada em conjunto pela Associação Nacional dos Procuradores do Trabalho - ANPT, Associação Nacional dos Magistrados da Justiça do Trabalho - ANAMATRA, Associação Brasileira dos Advogados Trabalhistas ABRAT e Sindicato Nacional dos Auditores Fiscais do Trabalho - SINAIT foi capaz de provocar uma discussão mais profunda entre os deputados e senadores. Enfim, no dia 13 de julho de 2017, pouco mais de 180 dias após a apresentação do Projeto de Lei na Câmara dos Deputados, foi sancionada, sem qualquer alteração pelo Senado federal, a Lei 13.467/2017, conhecida popularmente como reforma trabalhista que entrou em vigor a partir do mês de novembro de 2017. (ANPT, 2018)

O discurso de flexibilização das leis trabalhistas, que foi pregado durante anos e desaguou na reforma trabalhista de 2017, acabou por enfraquecer o próprio Direito do Trabalho, nas palavras de Vasconcelos Filho e Câmara (2017, p. 225):

Sendo assim, o Direito do Trabalho começa a sentir os efeitos de uma onda flexibilizatória e de desregulamentação de garantias anteriormente conquistadas, e, decorridos mais de 30 anos, o ápice desse desmonte é a materialização com a chamada Reforma Trabalhista, notadamente pela autorização legislativa de no processo negocial trabalhista serem subtraídos direitos constantes na legislação estatal.

Houve, portanto, sem o debate democrático necessário, uma significativa alteração da legislação trabalhista brasileira proposta e levada a cabo por um governo que chegou ao poder 
sem que tenha passado pelo crivo do voto dos eleitores, apoiada pelo empresariado em geral e duramente criticada pelos trabalhadores, sindicatos, Ministério Público do Trabalho e a Associação dos Juízes do Trabalho (MAIA, 2017).

A reforma trabalhista que entrou em vigor em novembro de 2017 é claramente prejudicial aos interesses dos sindicatos e especialmente dos trabalhadores. Em relação aos sindicatos, a alteração nos artigos 578 e 579 da CLT retirou o caráter obrigatório da contribuição sindical para os trabalhadores, tornando o seu recolhimento facultativo, ou seja, a reforma trabalhista diminuiu drasticamente a principal fonte de receita dos entes sindicais. Neste sentido, não é exagero afirmar que a própria subsistência dos sindicatos está em xeque após a reforma trabalhista, pois a retirada da obrigatoriedade da contribuição sindical, sem qualquer contrapartida para equilibrar ou, pelo menos, para possibilitar uma transição adequada irá fatalmente resultar em um enfraquecimento, ainda maior, do sindicalismo no Brasil.

De forma paradoxal, ao mesmo tempo que retirou a maior fonte de receita dos entes sindicais, a reforma trabalhista elevou a importância do negociado sobre o legislado, de tal maneira que as convenções e os acordos coletivos, firmados diretamente pelos sindicatos, podem, agora, inclusive subtrair direitos dos trabalhadores.

Em relação aos trabalhadores, além da possiblidade de supressão de direitos por meio de negociações coletivas, a reforma trabalhista de 2017 representou enorme precarização do trabalho ao retirar, dentre outras coisas: o direito às horas in intinere, possibilitar o trabalho de gestantes e lactantes em ambientes insalubres, acabar com a homologação da rescisão nos sindicatos, criar o "dano moral tarifado", permitir a "pejotização" e dificultar consideravelmente o acesso à justiça.

Apesar do evidente caráter prejudicial da reforma trabalhista e da declarada insatisfação, os sindicatos e trabalhadores brasileiros foram incapazes, antes, durante e depois da aprovação da lei, de se agregarem e exercer uma pressão que fizesse com que as autoridades (legisladores e Poder Executivo) recuassem em alguma questão. A inércia dos sindicatos e, consequentemente, dos trabalhadores diante de uma reforma trabalhista prejudicial foi espantosa e preocupante. Tal situação demonstra que o modelo sindical atual não é mais viável, tendo em vista a transformação do trabalho: 
O modelo sindical de raiz obreirista não mais se sustenta porque atores que resistiam ao paradigma clássico não são mais predominantes no atual mundo do trabalho. Assim o viés coletivo do Direito do Trabalho, através dos seus institutos principiológicos, modelo sindical, negociação coletiva, greve, necessitam ser revisitados e rompidos para se adequar as exigências da sociedade contemporânea (VASCONCELOS FILHO; CAMARA, 2017, p. 232).

Isso demonstra que nem um modelo sindical ideal (pluralista e livre), em virtude da transformação dos atores sociais e da individualização do trabalho já tratada neste artigo, conseguiria enfrentar de forma satisfatória alterações legislativas lesivas, como a reforma trabalhista. E menos ainda os sindicatos brasileiros que, longe do modelo ideal, são fundados no princípio da unicidade e do corporativismo. Vale aqui trazer o pensamento de Émile Durkheim quando criticava, no período de consolidação da sociedade industrial, a resistência de algumas instituições de sua época que ainda mantinham traços do ancien regime em suas lógicas de funcionamento:

Mas não há instituição que, num dado momento, não degenere, seja por não saber se modificar a tempo para se adaptar a novas condições de existência, seja por se desenvolver num sentido unilateral, exaurindo algumas de suas propriedades, o que a torna inapta para prestar serviços de que era encarregada. (DURKHEIM, 2017, p.32)

Nesta linha de pensamento, cabe a crítica ao modelo sindical que delineou sua natureza organizacional no cerne da revolução industrial; numa palavra, é preciso reconhecer que o sindicato já não possui estatura para lutar por melhores condições de trabalho ou, pelo menos, para entabular frentes de batalhas que evitem sua deterioração ou mesmo a existência de direitos historicamente conquistados pelos trabalhadores, mas que ainda se fazem necessários para a manutenção de suas dignidades.

\section{CONCLUSÃO}

As organizações sindicais parecem que não estão conseguindo se adaptar as profundas transformações que, desde os anos 1980, se projetam sobre os processos produtivos e as relações de trabalho. Com efeito, não estão mantendo o capital político que angariaram na primeira metade do século XX e que influenciou enormemente na construção dos modelos governamentais e nas políticas econômicas; atualmente, os sindicatos não conseguem influir de forma significativa na produção legislativa, de sorte que se assiste mundialmente a

\footnotetext{
Rev. de Movimentos Sociais e Conflitos | e-ISSN: 2525-9830 | Porto Alegre | v. 4 | n. 2 | p. 84 - 104 | Jul/Dez. 2018
} 
formulação de normas que contrariam seus interesses e os interesses dos trabalhadores como um todo.

No Brasil, o sistema sindical fundado no corporativismo e no princípio da unicidade sindical, que foi mantido pela Constituição Federal de 1988, demonstra-se ultrapassado. A constatação empírica deste fato foi demonstrada, especificamente no caso do sindicalismo brasileiro, com a reforma trabalhista de 2017. A proposta foi politicamente arquitetada e posta em execução sem que tenha sofrido, verdadeiramente, uma resistência que lhe impusesse limites ou recuos. De tal maneira que o projeto de Lei tramitou desde o início até sua conclusão no Senado Federal sem que os sindicatos aprovassem matérias substanciais ao projeto originário.

O que se assistiu neste evento conduz ao entendimento de que o discurso acerca da necessidade da flexibilização e da desregulamentação das leis trabalhistas, devido à intensa transformação tecnológica característica da produção capitalista contemporânea, continuará, cada vez mais, ganhando força e reunindo novos adeptos. Assim como, deve-se manter o engodo que não deixa distinguir o que é flexibilização e precarização das leis trabalhistas.

Por isto, é urgente que os sindicatos, enquanto atores sociais importantes na representação de interesses de parcela substancial da sociedade, voltem a ter protagonismo e possam resistir e negociar com isonomia as investidas legislativas que contrariam os desejos e necessidades dos trabalhadores. Vê-se, no Brasil, que se faz mister uma reformulação da lógica de funcionamento das organizações sindicais visando a retomada de seu capital político. É preciso saber se colocar frente à nova realidade do mercado de trabalho, em que predomina a fragmentação, a criação de inúmeras categorias e o enfraquecimento alicerçada na identidade construída no cotidiano da execução das tarefas semelhantes.

Deve-se questionar mais fortemente o princípio da unicidade sindical e se abrir espaço para a criação de mais de um sindicato por cada base territorial, possibilitando uma pluralidade sindical digna de um Estado Democrático de Direito. Enfim, as organizações sindicais devem incorporar as novidades tecnológicas como aliada, de sorte que as redes sociais e aplicativos de mensagem instantânea (Whatsapp e Telegram) devem ser instrumentalizadas para estruturação de novas formas de lutas.

\section{Referências}

Rev. de Movimentos Sociais e Conflitos | e-ISSN: 2525-9830 | Porto Alegre | v. 4 | n. 2 | p. 84 - 104 | Jul/Dez. 2018 
ADORNO, Theodor W; HORKHEIMER, Max. Conceito de iluminismo. São Paulo: Nova Cultura, 1991.

ALMEIDA, Claudio Aguiar. Cultura e sociedade no Brasil: 1940 - 1968. São Paulo: Atual, 1996.

ANPT - ASSOCIAÇÃO NACIONAL DOS PROCURADORES DO TRABALHO. Nota Técnica PLC 38/2017 - Reforma trabalhista aspectos de inconstitucionalidade e de antijuridicidade. Brasília. Disponível em: < https://goo.gl/n3fe2y >. Acesso em: 10/05/2018.

BAUMAN, Zygmunt. A Riqueza de Poucos Beneficia a Todos Nós. Rio de Janeiro: Zahar, 2015.

BELTRAN, Ari Possidonio. Os Impactos da Integração Econômica no Direito do Trabalho: globalização e direitos sociais. São Paulo: LTr, 1998.

BRASIL. CONSTITUIÇÃO DA REPÚBLICA FEDERATIVA DO BRASIL Brasília: Edição Administrativa do Senado Federal, 2015.

PROJETO DE LEI 6787/2016, DE 23 DE DEZEMBRO DE 2016. Altera o Decreto-Lei $\mathrm{n}^{\circ}$ 5.452, de $1^{\circ}$ de maio de 1943 - Consolidação das Leis do Trabalho, e a Lei n $^{\circ}$ 6.019, de 3 de janeiro de $1974 . \quad$ Em: http://www.camara.gov.br/proposicoesWeb/fichadetramitacao?idProposicao=2122076.

Acesso em: 15/05/2018.

CASSAR, Vólia Bomfim. Flexibilização dos direitos trabalhistas: prevalência do negociado coletivamente sobre o legislado. Revista de Direito do Trabalho, São Paulo, SP, v. 44, n. 187, p. 91-107, mar. 2018.

CASTELLS, Manuel. A Sociedade em Rede. São Paulo: Paz e Terra, 2016.

DELUIZ, Neise; TREIN, Eunice S. Trabalho e a qualificação profissional na visão de autores alemães. Boletim Técnico do Senac, Rio de Janeiro, v. 17, n. 1, p. 3-21, jan. /abr. 1991.

DURKHEIM, Émile. Lições de Sociologia. São Paulo: Martins Fontes, 2013.

FARIA, Antonio Augusto; DE BARROS, Edgard Luiz. Getúlio Vargas e sua época. Global Editora, 1983.

FARIAS, Clovis Renato Costa. Desjudicialização. Joinville: Clube de Autores, 2007.

FEIJÓ, Carmem A. do V. C.; CARVALHO, Paulo Gonzaga M de. A evolução recente da produtividade e do emprego na indústria brasileira. Rio de Janeiro: FASE, 1994.

FOLHA DE SÃO PAULO. São Paulo. Disponível em: < https://goo.gl/qC7AvD >. Acesso $10 / 06 / 2018$.

Rev. de Movimentos Sociais e Conflitos | e-ISSN: 2525-9830 | Porto Alegre | v. 4 | n. 2 | p. 84 - 104 |

Jul/Dez. 2018 
GORZ, André. Crítica da divisão do trabalho. São Paulo: Martins Fontes, 1989.

HABERMAS, Juergen. A nova instransparência - a crise do estado de bem-estar social e o esgotamento das energias útopicas. São Paulo: Novos Estudos CEBRAP, n. 18, setembro/1987.

HALL, Richard H. O conceito de burocracia: uma contribuição crítica. In: CAMPOS, Edmundo. Sociologia da burocracia. Rio de Janeiro: Zahar Editores, 1978.

HARVEY, David. Condição pós-moderna. São Paulo: Edições Loyola, 1992.

HEILBROBER, Robert L. A natureza e a lógica do capitalismo. São Paulo: Editora Ática, 1988.

IGLÉSIAS, Francisco. Trajetória Política do Brasil: 1500-1964. São Paulo: Companhia das Letras, 1993.

LEBRE, Eduardo Antonio Temponi. Direito Coletivo do Trabalho. Porto Alegre: Síntese, 1999.

MAIA, Gustavo. Aprovação ao governo Temer oscila de 3\% para 6\%, indica Ibope. Folha de S. Paulo, São Paulo, 20 dezembro 2017. Disponível em: < https://goo.g1/HdEGtP >. Acesso em:

MARCUSE, Herbert. A ideologia da sociedade industrial - o homem unidimensional. Rio de Janeiro: Zahar Editores, 1973.

MARX, Karl. O capital. São Paulo: Editora Betrand Brasil-Difel, 1987.

NASCIMENTO, Amauri Mascaro. Compêndio de Direito Sindical. São Paulo: LTr, 2008.

O GLOBO. Rio de Janeiro. Disponível em: < https://goo.gl/B1Ljaz >. Acesso em: $15 / 06 / 2018$.

PORTO, Ana Carla Vaz. O toyotismo e a precarização dos direitos trabalhistas. Revista de Direito do Trabalho, São Paulo, SP, v. 42, n. 170, p. 203-220, jul./ago. 2016.

RAGO, Margareth Luzia; MOREIRA, Eduardo F. P. O que é taylorismo. São Paulo: Editora Brasiliense, 1987.

RIBEIRO, Fabio Túlio Correia. A reforma trabalhista sob a ótica da cláusula de vedação ao retrocesso social, observada a força centrípeta das contingências econômicas: um novo round de uma velhíssima batalha. Revista do Tribunal Superior do Trabalho, São Paulo, SP, v. 83, n. 4, p. 95-155, out./dez. 2017. 
ROMITA, Arion Sayão. A globalização da economia e o poder dos sindicatos. Revista de Direito do Trabalho. São Paulo, n. 105, p. 13-23, jan./mar de 2002.

SILVA JÚNIOR, Antônio Braga da. Valorização do trabalho humano: uma diretriz constitucional esquecida em meio à crise econômica e às consequentes propostas flexibilizantes. Revista de Direito do Trabalho, São Paulo, SP, v. 43, n. 178, p. 91-115, jun. 2017.

SORJ, Bila. Sociologia e trabalho: mutações, encontros e desencontros. Revista Brasileira de Ciências Sociais, São Paulo, v. 15, n. 43, p. 25-34, jun. 2000.

SOUSA SANTOS, Boaventura de. Para um novo senso comum: a ciência, o direito e a política na transição paradigmática. São Paulo: Cortez Editora, 2000.

VASCONCELOS FILHO, Oton de Albuquerque; CAMARA, Maria Amália de Oliveira Arruda. Reforma trabalhista e seus impactos no sindicalismo de raiz obreirista: redesenhando o discurso sindical para ampliar os cânones de proteção no processo negocial coletivo. Revista dos Tribunais, São Paulo, v. 106, n. 985, p. 223-241, nov. 2017.

WEBER, Max. Economia e sociedade. Brasília: Editora da Universidade de Brasília (UnB), 1991.

WOOD, J. Stephen. Toyotismo e/ou japonização. In: HIRATA, Helena Sumiko. Sobre o modelo japonês. São Paulo: Editora da Universidade de São Paulo (USP), 1993. 